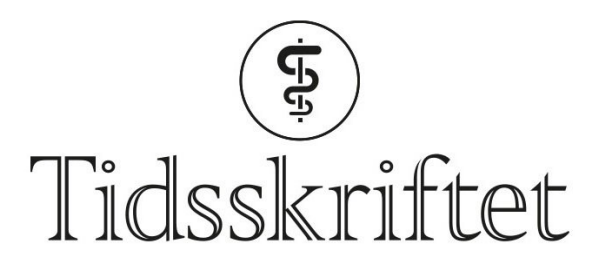

DEN NORSKE LEGEFORENING

\title{
Struktur og ledelse
}

INTERVJU

JANNIKE REYMERT

E-post: jannike.reymert@gmail.com

Bakklandet legekontor

Namsos

Faglig sett har Kjell Krüger hoppet fra tue til tue i et litt forvirrende mønster. Det har gitt ham en kompetanse han har hatt god bruk for som medisinsk leder av Avdeling for sykehjemsmedisin i Bergen.

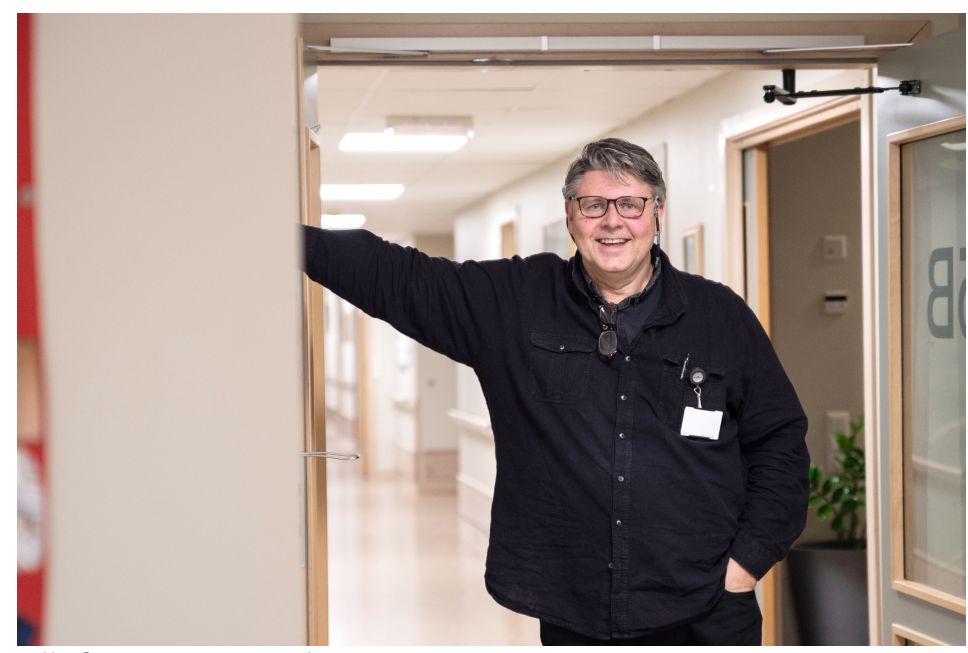

Alle foto: Magne Sandnes

- Jeg har alltid interessert meg for ledelse og hvordan man bygger miljøer som er gode å arbeide i. Det er kanskje en av de viktigste oppgavene man har som sjef, sier han.

Etter noen år i allmennpraksis valgte han å jobbe for legemiddelindustrien.

- Jeg tenkte at arbeidsfellesskapet kanskje fungerte bedre i en privat setting, og på mange måter var det slik. Jeg husker enda hvordan det varmet at noen hadde satt en blomst på skrivebordet mitt første arbeidsdag. Det er selvfølgelig litt banalt, men viktig likevel.

Da IT-boblen sprakk, skiftet han jobb på nytt, nå til IT-selskapet Sysdeco. De hadde kjøpt opp Profdoc, et dataprogram for allmennmedisin.

- Jeg har nok fått et industristempel etter disse jobbene, sier han lakonisk, men poengterer at det har vært en rød tråd i hans «IT-sidespor»:

- Medikamentmodulen vi utviklet i Profdoc Vision var strukturert for uttak av valid statistikk. Det har jeg alltid tenkt helsevesenet burde blitt bedre på. 


\section{Doven prisvinner}

- Jeg er doven, men liker å ha orden, forteller han når han skal forklare sin interesse for dataprogrammer.

- Vi kan ikke påstå at vi vet hva vi driver med hvis vi ikke får tilbakemelding på gruppenivå. Da er strukturerte programmer veien å gå. Når ting registreres på ensartet måte, får du tallene du trenger helt gratis i etterkant.

Kjell Krüger var leder i Legeforeningens IT-utvalg i fire år, men presiserer at han på ingen måte er noen IT-nerd.

- Min eneste interesse i dataprogrammer er å finne gode metoder for å få jobben gjort.

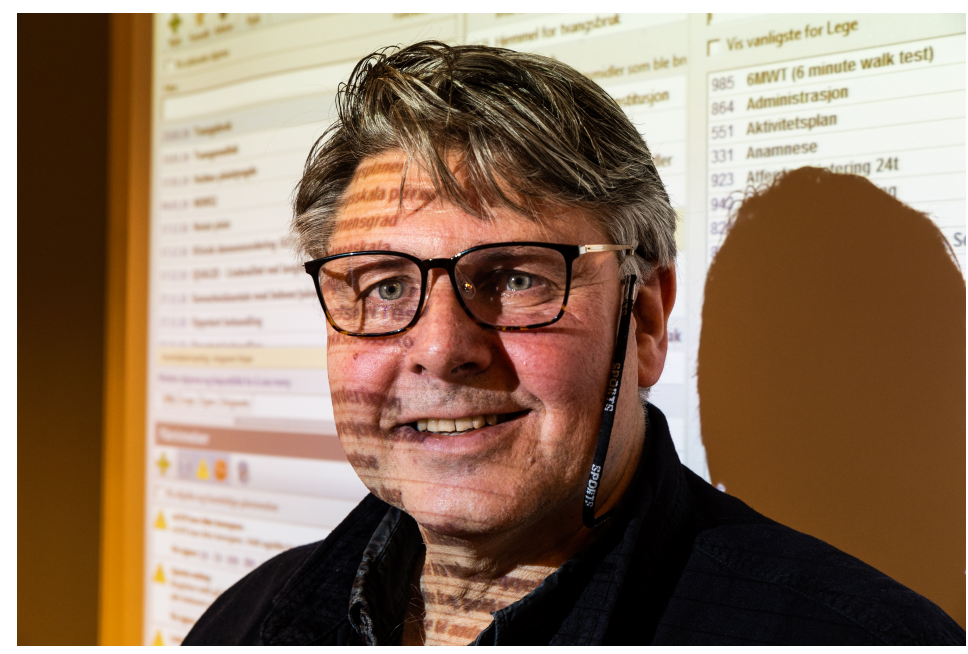

Han holder seg neppe helt til sannheten nå. I 2017 fikk han Bergen kommunes nyopprettede forsknings- og innovasjonspris for sin rolle i utviklingen av et nytt helsefaglig beslutningsstøttesystem. I prisomtalen omtales journalsystemet for sykehjem å ha både lokal og nasjonal viktighet, blant annet fordi det muliggjør forskning i sykehjem i et helt annet format enn før. Systemet er utviklet sammen med lege og utvikler Magne Rekdal.

- Han er IT-mannen i prosjektet, mens jeg har bidratt med å tilpasse det virkeligheten i sykehjemmene, kommenterer Krüger.

Han forteller at prisen egentlig er for hele omorganiseringen han har ledet i sykehjemmene i Bergen.

- Vi er stolte av at tre sykehjem nå er godkjent som utdanningsinstitusjon der allmennleger i spesialisering kan ta sykehusåret sitt. Dessuten kan leger i spesialisering i indremedisin og i geriatri få deler av gruppe 2-tjenesten sin hos oss.

\section{Nye toner for sykehjemsleger}

Kjell Krüger undrer seg over at ikke geriatrien ser på sykehjemmene som en arbeidsplass for sine spesialister.

- Med eldrebølgen er det åpenbart at vi må dra lasset i lag for å få et godt helsetilbud til de syke eldre, sier han.

I 2013 fikk han frie tøyler til å heve statusen til sykehjemslegearbeidet i Bergen. I mange år var dette små bistillinger som byens allmennleger var pålagt. Statusen var deretter.

Krüger lister opp punktvis hvilke mål de satte seg:

- For det første lagde vi en egen enhet for sykehjemsmedisin her på Løvåsen sykehjem. Videre lagde vi en liten og utvidet ledergruppe med 15 leger fra ulike spesialiteter for å veilede de unge legene. De ble ansatt i store stillingsbrøker på minst 50\%, helst 10o \%. Tre leger ble teamoverleger, med ansvar for hver av de tre geografiske sektorene i byen, sier Krüger. 


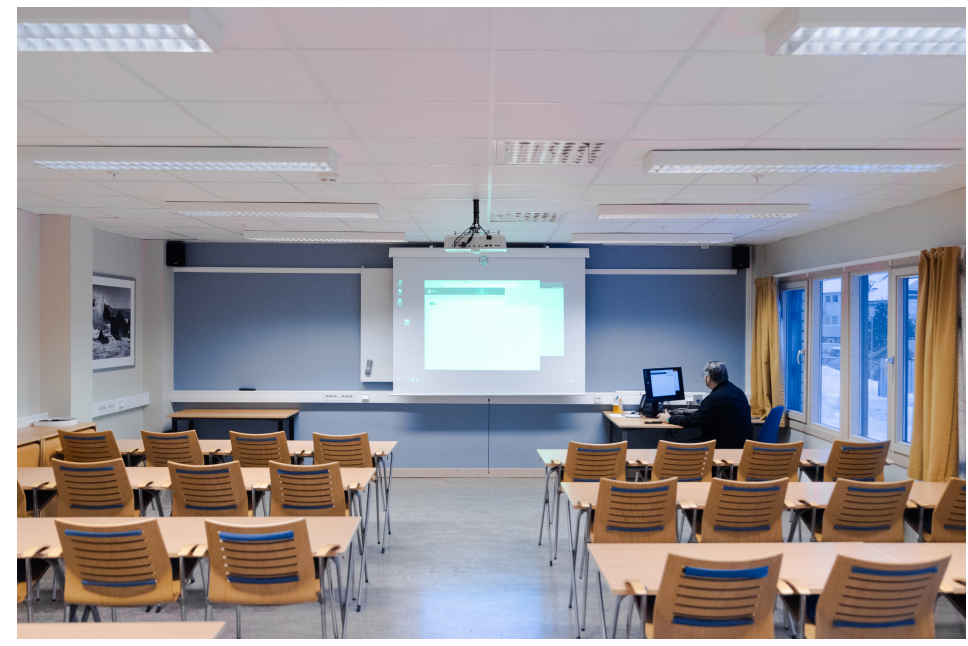

Legene møtes til internundervisning to timer hver måned, og har «teamundervisning» innimellom dette.

- Dette er kulturbygging. Sykehjemslegene i byen blir bedre kjent og slipper å stå alene når de trenger hjelp, legger han til.

Krüger forteller videre at de utviklet Sykehjemshandboka.no. Den ligger på Helsebiblioteket og brukes nå av mange sykehjemsleger i landet.

Smålåten er han ikke når vi snakker om hans hjertebarn. Dovenskapen han skrøt av i stad står ikke til troende, tenker jeg, mens han fortsetter enetalen og teller poengene sine på to hender.

- Dette er en storbymodell. Vi kan ikke ha geriatere i hele landet. Derfor er det så viktig at sykehjemsleger får et eget utdanningsløp som gjør det mer attraktivt for de unge å velge dette karriereløpet.

\section{Myter i medisinen}

Krüger så fort at det var et skrikende behov for et bedre dataverktøy i sykehjemssektoren.

- Bare tenk deg å få tilsyn fra myndighetene og måtte innrømme at vi faktisk ikke vet hva vi driver med! Nå kan vi med få tastetrykk legge frem data som viser fordelingen av tvangsvedtak, bruken av psykofarmaka og liggesår på alle sykehjemmene våre. For øvrig skal vi ikke bare registrere og lage statistikk. Kunnskapen vi får, må gis tilbake til medarbeiderne. Vi bruker dem derfor aktivt i medarbeidersamtaler, sier han.

Fremover ser han det som sin hovedoppgave å få ferdig et datasett som sikrer kvalitetsarbeidet ved sykehjemmene i Bergen.

- Vi kan ikke skru tiden tilbake og si at det er bra nok å ha en virksomhet der journalnotater er det eneste skriftlige legene produserer, sier han, og utdyper:

- Nå har vi for eksempel sett på fall hos beboerne. Blant 2300 pasienter er det til sammen registrert 700-80o fall. Vi analyserer nå forhold som kan si noe om risikoen for fall. Vi ser at de eldste og de tynneste samt de som har påvist ortostatisme, faller mest.

Han avbryter seg selv og sier:

- Det er så mange myter vi må avlive! I våre sykehjem er ikke pasientene underernært. Gjennomsnittlig kroppsmasseindeks (BMI) er 23,4. Vi følger tallene til enhver tid. Omtrent $18 \%$ har BMI under 20. Alder og morbiditet tatt i betraktning er ikke dette annet enn forventet. 


\section{Kjell Krüger}

Født 14.11.1952

Cand.med., Universitetet i Oslo og Freie Üniversität Berlin 1979

Allmennpraktiker Den norske legeforening 1987

Medlem av Forskningsrådets programstyre for medisin/IT 1998-2006

Sykehjemsoverlege, Løvåsen sykehjem 2005-13

Master i helseadministrasjon, Universitetet i Oslo 2006

Spesialist i indremedisin og i geriatri, Universitetet i Bergen 2006

Styremedlem, Nasjonalt senter for elektronisk pasientjournal 2004-07

Formann Legeforeningens IT-utvalg 2003-07

Ph.d. Universitetet i Bergen 2013

Avdelingsoverlege, avdeling for sykehjemsmedisin, Bergen kommune 2013-d.d.

Førsteamanuensis ved Senter for alders- og sykehjemsmedisin, 2013-d.d.

Nå har han snakket seg varm. Han er nok ikke mer doven enn at han har planlagt hva han vil ta opp i intervjuet.

- For øvrig synes jeg nullvisjonen om nevroleptika og B-preparater i sykehjem har gått for langt. Pendelen har vippet slik at mange kan lide unødig fordi legene vegrer seg mot å forskrive selv små doser av disse medikamentene, sier han, før han legger til at forhold rundt medisinering av eldre et felt der forskning kan gi oss mye nyttig kunnskap.

Den akademiske karrieren ble lagt på is etter doktorgraden.

- Jeg er ikke en akademisk type, jeg er en praktiker, slår han fast.

- Men i våre dager må man jo ha doktorgrad for å bli hørt. Jeg slet meg gjennom dette arbeidet fordi vi hadde midler til å se på effekten av beslutningstøtte på medisinske parametere i journalprogrammet, sier han, og trekker frem et eksempel:

- På et av tre sykehjem fikk 50 \% av pasientene nevroleptika. Da legene så dette, begynte prosenten å gå ned mot gjennomsnittet for flere institusjoner. Nytten av å se på slike forhold er at de som har høyest forbruk, lett endrer forskrivningspraksis når de får vite at de avviker fra gjennomsnittet. Vi må likevel huske på at det ikke finnes noen fasit her. Kanskje er det riktig forskrivning selv om sykehjemmet ligger over gjennomsnittet?

\section{Livets siste dager}

Det er ingen tvil om at Kjell Krüger trives med arbeidssituasjonen sin.

- Hva er det som driver deg?

- Jeg er nok avhengig av å ha et prosjekt jeg kan bruke energien min på. Jeg synes rett og slett det er artig å få jobbe med å utvikle den datapakken vi nå nesten er i mål med. Det oppleves som meningsfylt.

- Hva er du mest stolt av?

- Jeg har aldri hatt en helhetlig plan for min karrierevei. På mange måter har skjebnen ført meg fra jobb til jobb, men i ettertid ser jeg at jeg har bygd sten på sten til jeg nå avslutter yrkeslivet med å gjennomføre nåværende prosjekt. Jeg føler at det er en flott måte å avslutte yrkeslivet på. 


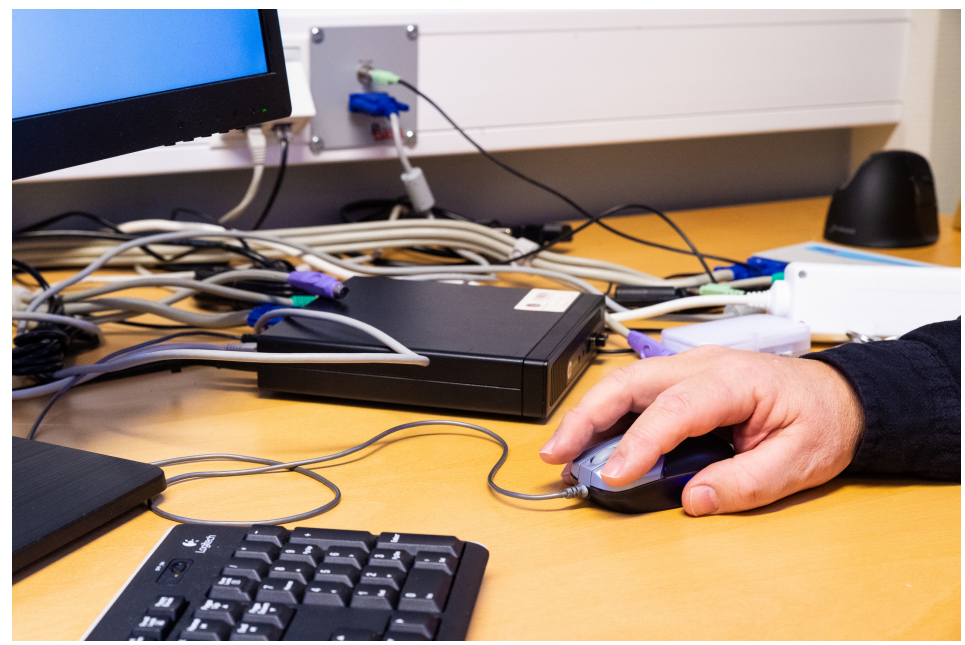

- Sykehjemmene fungerer på en måte som dødens forgård. Tenker du at vi er i mål med gode pasientforløp når livet går mot slutten?

- Jeg synes pleierne gjør et veldig godt arbeid her, både rent praktisk og når det gjelder omsorg for pasienter og pårørende. Den medisinpakken vi nå bruker har forenklet legens jobb betraktelig. Man kan føle seg trygg på at det som gis, er nyttig. Vi har også erfart at gode prosedyrer er nøkkelen til suksess. Sjekklister og kommunikasjon må legges på et så enkelt nivå at alle kan være med. Jeg tenker at vi har truffet godt siden vi med nesten 1 ooo dødsfall per år på sykehjemmene i Bergen har så få klager på forhold rundt døende pasienter.

Også nå har han mer på hjertet:

- HLR-statusvurdering er vanskelig, men det er en tydelig bestilling fra sykehusene om at dette skal klarlegges på sykehjemmene. Den nasjonale prosedyren på dette området er jo så omfattende at den kanskje kan virke noe hemmende på beslutningene. Kan vi forsvare en litt mindre omfattende tilnærming? spør han.

Han lar det henge i luften før han fortsetter:

- Dette er ikke enkelt. Hva de eldre selv sier når de snakker om hvordan de vil ha det i livets siste dager, gjør inntrykk på meg. Jeg husker for eksempel meget godt et ektepar som nærmet seg de 9o, men fremdeles var oppegående og hjemmeboende. Jeg spurte dem om de ville ha behandling for å forlenge livet hvis de hadde fast plass på sykehjem. Han sa ja, hun sa nei.

- Jeg husker også en annen pasient som lå lenge på det siste. Han forsto nok at vi vurderte om vi skulle fortsette å behandle ham aktivt. Da han samtalte med kona om det, var hennes gråt svar nok. Det er ikke enkelt, gjentar han.

- Mange sykehjem har innført forberedende samtaler der man åpner for å snakke med pasientene om døden og hvordan de vil ha det når livet nærmer seg slutten. Har du noen tanker om denne tilnærmingsmåten?

- Jeg tenker at man lett kan kommunisere for tydelig at døden nærmer seg. Skal man ikke tillate seg å være litt tilbakeholden og la folk beholde et lite håp? Jeg tror ikke alle pasienter er klare for å snakke om dette. For ikke så få er det kanskje like godt å leve livet i en drøm om fremtiden, etter hvert få morfin og så gli inn i evigheten.

Publisert: 5. mars 2019. Tidsskr Nor Legeforen. DOI: 10.4045/tidsskr.19.0087

(C) Tidsskrift for Den norske legeforening 2020. Lastet ned fra tidsskriftet.no 